\title{
Engenharia de sistemas complexos
}

\author{
JOSÉ RoBERTO CASTILHO PIQUEIRA I \\ e SÉRGIO MASCARENHAS DE OLIVEIRA II
}

\section{Introdução}

$\mathrm{O}$ ROMPIMENTO da barragem, ocorrido recentemente em Mariana (MG), coloca para a engenharia algumas perguntas de relevância que vão desde o trato de questões ambientais até aquelas relativas ao monitoramento e manutenção de sistemas operantes, com riscos à população.

A engenharia brasileira, de extrema competência e provida de especialistas de alto nível dentro e fora das universidades, por problemas econômicos e políticos é, de maneira geral, lembrada apenas quando essas grandes catástrofes acontecem.

Grandes catástrofes, entretanto, têm o lado positivo de obrigarem que ações preventivas e melhorias operacionais sejam buscadas e implementadas.

Todos sabem que o malogro em uma missão de treinamento em 1967 levou os Estados Unidos a aprimorarem seu programa espacial, levando-os à Lua, em 1969. Isso, entretanto, não impediu outra catástrofe em missão espacial, nos anos 1980, indicando que os riscos andam junto com a engenharia e a tecnologia.

A tragédia em um voo Brasil-França, no Aeroporto de Orly, em 1973, levou à proibição do acendimento de cigarros e similares em todo e qualquer tipo de viagem aérea. Mas o progresso da aviação não nos leva à total segurança, fato amplamente conhecido e fundamentado nos desastres aéreos que ocorrem com relativa frequência.

Esses eventos nos levam a pensar se não é possível melhorarmos nossos modelos de análise de riscos e previsões de catástrofes fazendo uso da grande quantidade de dados disponíveis e das facilidades computacionais e de seu processamento e identificação.

Mais ainda, se esses fenômenos aparentemente inesperados não têm um elo comum. Assim, a queda de um avião, o rompimento de uma barragem, um acidente vascular-cerebral, um congestionamento urbano, o pânico em uma multidão ou uma mutação genética talvez possam ser modelados e estudados com uma abordagem comum, originária dos conceitos relativos aos sistemas dinâmicos complexos.

É dessa ideia que este ensaio trata, buscando estabelecer um tipo de engenharia, de origem multi e transdisciplinar, considerando as dinâmicas não li- 
neares e caóticas dos sistemas físicos e biológicos, combinadas com a imensa capacidade computacional hoje disponível.

\section{Origens da engenharia dos sistemas complexos}

A engenharia acompanha o ser humano desde suas origens. A obtenção do fogo, de vestimentas, habitações e o tratamento de metais para a construção de armas e ferramentas permitiu a sobrevivência da espécie.

Os romanos construíram aquedutos, estradas, barragens, pontes, sistemas de distribuição de águas e de coleta de esgotos em palácios, antes de a física se estabelecer como ciência.

A atividade da engenharia era vista como intelectualmente menor, própria dos artífices e artesãos, que passavam seu conhecimento sem preocupação com sistematização ou metodologia. Pertencia ao mundo dos trabalhadores braçais, e os intelectuais preocupavam-se com questões filosóficas e metafísicas.

Os exércitos, entretanto, perceberam a importância da engenharia para as batalhas e a arte de construir passou a ser sistematizada, com seu ensino incorporado ao treinamento de oficiais de maior patente.

As escolas de navegação foram decisivas para os descobrimentos, nos século XV e XVI. O domínio das técnicas de construção naval e da prática de conduzir navios tornou-se essencial para as nações que procuravam expandir suas fronteiras e buscar riquezas.

Essa era a engenharia até o final do século XVII: técnicas de construção de pontes, dutos, armas e navios, reproduzindo os traços empíricos herdados das gerações anteriores, restritas ao âmbito militar.

Nesse contexto, já se desenhava a complexidade nos trabalhos de caráter prático, envolvendo grandes estruturas e um considerável desconhecimento das condições possíveis de operação.

As Leis de Newton, que haviam sido propostas no início do século XVIII, deixaram de ser vistas apenas como filosofia da natureza, sendo incorporadas aos trabalhos de engenharia, que ganharam contornos de sistematização, com as construções sendo pensadas como projetos.

Assim, durante o século XIX, a engenharia passou a combinar o empirismo com os princípios físicos e químicos e, com a ajuda da matemática, produziu materiais mais eficientes, utilizados nas construções, na agricultura e nos ambientes domésticos.

O entendimento da termodinâmica levou à construção de ferrovias, transportando o progresso e povoando locais remotos, além da possibilidade de construir máquinas, iniciando a industrialização macanizada.

No final do século XIX e início do século XX, o fenômeno da indução eletromagnética, relatado por Michael Faraday, permitiu o transporte e o provimento de grandes blocos de energia e a implementação de circuitos para a comunicação a distância. 
Assim, apoiados nas ciências, grandes desafios foram enfrentados com sucesso: estradas, pontes, eletrificação, automóveis, rádio e televisão, computadores, laser e fibras ópticas, telefone, exploração do espaço, aviões são as maravilhas que, em pouco mais de 50 anos revolucionaram nossas vidas.

Olhando de perto, todas as técnicas de projeto dessas maravilhas baseiam-se em simplificações da realidade e, diante do desconhecido, fatores de segurança são introduzidos, com uma grande contribuição da teoria de probabilidades e dos processos estocásticos.

Do progresso tecnológico descrito nascem os sistemas complexos ou os "sistemas de sistemas" cada vez mais presentes no cotidiano. Para o bem, com os algoritmos computacionais das redes neurais, por exemplo, e, para o mal, com os surpreendentes acidentes.

Apesar de todo conhecimento acumulado, deparamos, diariamente, com a surpresa chamada, em linguagem técnica, de emergência. Isto é, quando partes se reúnem formando um todo, comportamentos que não são meras superposições de comportamentos individuais aparecem.

Outro fator a ser considerado é a extrema sensibilidade às condições iniciais que alguns sistemas apresentam. Pequenas perturbações em sistemas aparentemente robustos geram comportamentos muito diferentes dos esperados.

Essas são as duas características fundamentais dos sistemas complexos: emergência e sensibilidade às condições iniciais. Na próxima seção, essas ideias serão apresentadas no contexto de trabalhos seminais realizados durante o século XX.

\section{Os caminhos da engenharia dos sistemas complexos}

Há uma grande diversidade na identificação das origens do estudo dos sistemas complexos, pois os pesquisadores que se dedicaram ao assunto, consciente ou inconscientemente, são de origens tão variadas que o que se sabe hoje é quase uma criação coletiva de toda comunidade científica.

Entretanto, os passos iniciais foram dados pelo matemático francês Henri Poincaré (1854-1912), que, ao estudar o problema dos três corpos (Poincaré, 1981), mostrou que sistemas determinísticos, descritos por equações diferenciais não lineares, podem apresentar comportamentos de grande sensibilidade às condições iniciais, base do conceito de caos determinístico, popularizado nos anos 1980.

Há, além disso, duas figuras de grande relevância para o mundo da complexidade: Claude E. Shannon (1916-2001) e Allan M. Turing (1912-1954). Turing, estabelecendo os conceitos de computabilidade e de "Máquina de Turing", paradigma abstrato para a computação, que levou ao desenvolvimento das máquinas (Schechter, s. d.), e Shannon, desenvolvendo a "Teoria da Informação" (Shannon; Weaver. 1963), semente das telecomunicações avançadas.

Assim, Shannon e Turing, de maneira independente, trabalhavam, simultaneamente, em comunicações e computação, dois tópicos que, combinados, 
hoje proporcionam recursos antes inimagináveis para o mundo moderno das artes, da ciência, da medicina, da tecnologia e das interações sociais.

A invenção do transistor e a miniaturização em larga escala dos circuitos eletrônicos impulsionaram definitivamente a computação e as comunicações na segunda metade do século XX, permitindo que problemas com soluções analíticas não conhecidas ou difíceis de obter seguissem caminhos utilizando métodos numéricos.

Projetos de grande porte e de alto grau de dificuldade passaram a ter a simulação computacional como importante aliada, desvendando comportamentos dinâmicos em situações fisicamente complicadas, com parâmetros não mensuráveis influenciando nos processos.

Os dispositivos de memória, cada vez menores e mais baratos, combinados com a alta capacidade de processamento dos microprocessadores modernos, permitem o tratamento de grandes massas de dados, com poderosos algoritmos de identificação e reconhecimento de padrões (Northrop, 2011).

Assim nasce a engenharia dos sistemas complexos: fenômenos não lineares com sensibilidade a condições iniciais e emergência podem ser modelados de maneira precisa, podendo ser estabelecidas medidas de complexidade e, com elas, estudar possíveis regularidades de fenômenos considerados aleatórios.

\section{Medidas de complexidade}

Ao se tratar um sistema complexo como pertencente a uma atividade de engenharia, o primeiro passo a ser dado é estabelecer uma maneira de se executar algum tipo de medida que permita comparar dois sistemas diferentes.

A primeira medida proposta para a complexidade se deve a Andrei Kolmogorov (1903-1987), definida como o número de operações necessárias para a execução de um programa, isto é, para a execução de um conjunto de algoritmos (Kolmogorov, 1965), e chamada de complexidade computacional.

Uma maneira equivalente para a medida de complexidade computacional origina-se no conceito de entropia informacional, proposto por Shannon (Shannon; Weaver, 1963), e tem origem no mundo das comunicações, considerando-se que um sistema proposto com essa finalidade é composto por uma fonte capaz de emitir sequências de dados, um meio através do qual a sequência transita, atingindo um receptor, destino da mensagem.

Para a discussão aqui estabelecida, interessa a medida de informação associada a uma sequência, escolhida entre as diversas sequências possíveis de emissão pela fonte.

A abordagem é probabilística, associando-se às diversas sequências, suas probabilidades de ocorrência, e definindo-se informação individual como sendo uma variável aleatória que assume valores altos para sequências pouco prováveis e baixos, para as muito prováveis.

Ao valor esperado (média) dessa variável aleatória é dado o nome de entropia informacional e sua unidade é bits por sequência. Assim, a entropia infor- 
macional é relativa à fonte como um todo e, diferindo da complexidade algorítmica, não está associada a uma sequência individual, mas a todas as sequências possíveis de serem emitidas pela fonte.

Embora esse conceito não tenha, inicialmente, a proposta de medir complexidade computacional, pode perfeitamente servir para isso. Basta pensar que, dado um programa, é possível criar diferentes sequências para realizá-lo e atribuir a cada uma delas um valor de probabilidade.

A medida de complexidade computacional, do ponto de vista informacional, pode ser dada pela entropia de Shannon, que assume valor máximo caso todas as sequências sejam equiprováveis (Shannon; Weaver, 1963). É possível demonstrar que as duas medidas de complexidade computacional, de Kolmogorov e de Shannon, são equivalentes (Desurvire, 2009).

A tentativa de transportar o conceito de complexidade computacional para os sistemas naturais, regidos pelas leis da termodinâmica, parece uma inconsistência, pois sistemas na situação de equilíbrio termodinâmico, situação pouco complexa, apresentam entropia máxima.

Assim, novas propostas de medidas de complexidade foram apresentadas, considerando a máxima complexidade em situações em que as medidas de equilíbrio e desequilíbrio de um sistema se equivalem (López-Ruiz et al., 1995; Shiner et al., 1999).

López-Ruiz, Mancini e Calbet (1995) propuseram a chamada medida LMC para a complexidade. Shiner, Davison e Landsberg (1999) modificaram ligeiramente a medida LMC, definindo a medida SDL de complexidade, sendo, ambas, qualitativamente equivalentes (Piqueira, Campbell-Borges, 2013).

\section{Conclusões}

As ideias aqui apresentadas têm sido aplicadas em vários problemas reais: em ecologia (Piqueira; Mattos; Vasconcellos Neto, 2009), em economia (Piqueira; Mortoza, 2012), em neurociência (Piqueira; Lima; Batistela, 2014), em física de partículas (Panos et al., 2007).

Usar as medidas de complexidade e sua dinâmica temporal em problemas complexos de engenharia deve produzir maneiras de realizar projetos complexos e de previnir desastres.

\section{Referências}

DESURVIRE, E. Classical and Quantum Information Theory. Cambridge, UK: Cambridge University Press, 2009.

KOLMOGOROV, A. N. Three approaches to the definition of the concept "quantity of information". Problemy Peredachi Informatsii, v.1, p.3-11, 1965.

LÓPEZ-RUIZ, R.; MANCINI, H. L.; CALBET, X. A statistical measure of complexity. Physics Letters A, v.209, p.321-6, 1995. 
NORTHROP, R. B. Introduction to complexity and complex systems. Flórida: CRC Press, 2011 .

PANOS, C. P.; CHATZISAVVAS, K. C.; MOUSTAKIDIS, C. C.; KYRKOU, E. G. Comparison of SDL and LMC measures of complexity: Atoms as a testbed. Physics Letters $A$, v.363, n.1/2, p.78-83, 2007.

PIQUEIRA, J. R. C.; CAMPBELL-BORGES, Y. C. Extending SDL and LMC complexity measures to quantum states. Physica. A, v.392, p.5255-9, 2013.

PIQUEIRA, J. R. C.; LIMA, V. M. F. DE; BATISTELA, C. M. Complexity measures and self-similarity on spreading depression waves. Physica. A, v.401, p.271-7, 2014.

PIQUEIRA J. R. C.; MATTOS S. H. V. L. de; VASCONCELLOS NETO, J. Measuring complexity in three-trophic level systems. Ecological Modelling, v.220, n.3, p.266$71,2009$.

PIQUEIRA, J. R. C.; MORTOZA, L. P. D. Brazilian exchange rate complexity: financial crisis effects. Communications in Nonlinear Science \& Numerical Simulation, v.17, n.4, p.1690-5, 2012.

POINCARE, H. Le probléme des trois corps. Revue Générale des Sciences Pures et Appliquées, v.2, p.1-5, 1891.

SCHECHTER, L. M. A vida e o legado de Alan Turing para a Ciência. Disponível em: <www.dcc.ufrj.br/ luisms/turing/seminarios.pdf>.

SHANNON, C. E.; WEAVER, W. The mathematical theory of communication. Urbana; Chicago: Illini Books Edition, 1963.

SHINER, J.; DAVISON, M.; LANDSBERG, P. Simple measure for complexity. Physical Review E, v.59, n.2, p.1459-64, 1999.

RESUMO - Este artigo apresenta uma proposta de abordagem dos sistemas complexos considerando sua engenharia e definindo medidas cujas evoluções temporais proporcionam indicativos de necessidade de ações preventivas nas fases de projeto, execução e operação de grandes obras.

PALAVRAS-CHAVE: Aleatoriedade, Complexidade, Informação, Projeto.

ABSTRACT - This paper proposes an approach to complex systems considered as engineering works, and defines measures whose temporal evolutions give hints of the need for preventive actions in the design, execution and operation of big systems.

KEYWORDS: Randomness, Complexity, Information, Design.

José Roberto Castilho Piqueira é pesquisador $1 \mathrm{~A}-\mathrm{CNPq}$ e membro efetivo da Academia Nacional de Engenharia. @ - piqueira@lac.usp.br

Sérgio Mascarenhas de Olibveira é professor emérito do Instituto de Física de São Carlos, Universidade de São Paulo. @ - sergiomascarenhas28@gmail.com

Recebido em 2.12.2015 e aceito em 16.12.2015. 


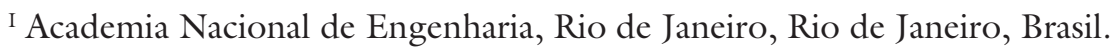

II Instituto de Física de São Carlos, Universidade de São Paulo, São Carlos, São Paulo, Brasil. 